\title{
EPISTOLARIO DE NIETZSCHE: APARATO CRÍTICO 1887-1889
}

- KGB III: Müller-Buck, Renate (ed.), Nachbericht zur dritten Abteilung. Dritter Teilband. Briefe von und an Friedrich Nietzsche. Januar 1887 - Januar 1889. Gesamtregister zur dritten Abteilung, 2 tomos,

- Berlin/New York: Walter de Gruyter, 2004. ISBN 3-11-015060-3.

Tal y como dijimos desde estas mismas páginas, una de las ventajas de la edición del epistolario de Nietzsche frente a la de sus obras es la rapidez -y el orden y la calidad, añadimos ahora-con el que los respectivos volúmenes de comentario crítico (Nachbericht) han ido apareciendo ${ }^{1}$. Sin embargo, no cabe duda de que constituye una sorpresa así como un gran motivo de satisfacción para los estudios nietzscheanos la repentina publicación del volumen que contiene el comentario a las cartas de y a Nietzsche fechadas entre enero de 1887 y enero de 1889. Es decir, las cartas que en la edición Colli-Montinari se hallan recogidas en los volúmenes KGB III/5 (cartas de Nietzsche) y III/6 (cartas a Nietzsche).

Este volumen de comentario crítico, el III 7/3, se presenta dividido, a causa de su gran extensión (1215 pp.), en dos tomos. En el primero hallamos el prólogo de los editores (pp. V-VIII), las cartas añadidas (pp. 3-12), un listado de cartas de las que únicamente se conserva la copia manuscrita realizada por Elisabeth (pp. 15-42) y el comentario crítico a las cartas escritas por Nietzsche entre enero de 1887 y enero de 1889 (pp. 53-572), o, lo que es lo mismo, al volumen III,5. En el segundo, además del aparato crítico a las cartas escritas a Nietzsche entre las mencionadas fechas (pp. 573-836), se publica también un listado de cartas no conservadas (pp. 839-852), un apéndice que recoge distintos documentos (pp. 859-1114), las correcciones (pp. 1117-1126) y, por último, un índice de la tercera sección del epistolario (pp. 1129-1214), es decir, un índice que abarca las cartas de y a Nietzsche fechadas entre enero de 1880 y enero de 1889 . Pero vayamos por partes.

La estructura de este volumen es, como hemos visto, similar a la de los otros Nachberichten ya publicados y se inicia, por tanto, con un prólogo firmado por

${ }^{1}$ El orden de aparición de estos comentarios críticos o Nachberichten al epistolario de Nietzsche editado en la edición Colli-Montinari (KGB) es el siguiente: El I/4 (octubre 1849 abril 1869) en 1993, el II/7.1 (abril 1869 - mayo 1872) en 1998, el II/7.2 (mayo 1872 - diciembre 1874) en 2000, el II/7 3.1 y 2 (enero 1875 - diciembre 1879) en 2001, el III/7.1 (enero 1880 - diciembre 1884) en 2003 y el III/7.2 (enero 1885 - diciembre 1886) en 2003. Un comentario a estos dos últimos volúmenes puede leerse en Estudios Nietzsche, 3 (2003), 183-184 y 4 (2004), 219-222, respectivamente. 
los editores del comentario crítico a la sección tercera de la KGB (Norbert Miller, Annemarie Pieper y Renate Müller-Buck), fechado en noviembre de 2004, y en el que, además de anunciarnos que con el presente volumen se da por concluida la edición del epistolario ${ }^{2}$ y que a partir de ahora los esfuerzos se van a centrar en la elaboración de los comentarios que aún faltan de las obras, se destaca el papel casi heroico de Renate Müller-Buck al haber realizado todo este trabajo excepcional en un tiempo record y con graves problemas en lo que a la financiación se refiere.

Los editores destacan también la especial significación del epistolario de estos dos últimos años de la vida lúcida de Nietzsche, pues en este periodo cobra mayor importancia y se enfatiza aún más la ya de por sí gran articulación existente entre las cartas, las obras y las múltiples anotaciones que Nietzsche dejó manuscritas en cuadernos y folios ${ }^{3}$.

Este breve prólogo finaliza con un acto de honestidad intelectual, pues las dos últimas páginas contienen una enorme lista de agradecimientos destinados no únicamente a organismos oficiales o instituciones privadas, sino también a un notable grupo de personas (la mayoría de ellas estudiosos de diferentes países) que han contribuido de una u otra forma en la realización de este volumen.

Tras estas palabras de los editores nos encontramos con los 'añadidos' (Nachträge), es decir, aquellos documentos epistolares que no fueron publicados en los volúmenes correspondientes y que se han descubierto más tarde. Aún así, de esta lista (13 para KGB III/5 y 6 para KGB III/6) casi la mitad ya fueron publicados también como "añadidos" al final de los volúmenes ya mencionados o bien en el volumen final de la $\mathrm{KSB}^{4}$. De los documentos por vez primera publicados en la edición Colli-Montinari, cabe destacar la aceptación y por tanto inclusión (algo que no hizo en su momento Montinari) de la famosa nota que Nietzsche escribió alrededor del 3 de enero de 1889 a Cosima Wagner con las palabras «Ariadne, ich liebe Dich! Dionysos» ${ }^{5}$.

${ }^{2}$ Con esta afirmación se confirma la renuncia, como ya se había indicado en los planes de la edición en KGB III/7.2, al prometido volumen complementario, incluso se había hablado de hacer una sección cuarta de testimonios sobre Nietzsche con cuatro volúmenes y un quinto de comentarios, con los documentos de los once años de enfermedad (enero 1889 - agosto 1900). También se renuncia, por lo que aquí se dice, a la publicación de un volumen III/8 con un Register que cubriría todo el epistolario de Nietzsche desde 1849 hasta 1889. Sin embargo, en la p. VII se anuncia un volumen a modo de apéndice que servirá tanto para las obras como para las cartas.

${ }^{3}$ Para la cuestión biográfica, véase, por ejemplo, las pp. 410-532 del volumen tercero de la versión castellana (tr. de Jacobo Muñoze Isidoro Reguera, Madrid: Alianza, 1985) de la biografía de Nietzsche realizada por Curt Paul Janz (pp. 510-668 del segundo volumen en el original alemán editado en Carl Hanser Verlag, Wien: München, 1978, segunda edición revisada en 1993, 1981 en DTV). En lo que se refiere a los sucesos de los primeros días de enero de 1889, véase las pp. 9-39 del volumen cuarto de la mencionada biografía (en el original pp. 9-48 del volumen tercero, publicado por vez primera en 1979).

${ }^{4}$ Tanto los añadidos como el índice onomástico, que se encuentran en el volumen octavo, fueron publicados en 1987 para los lectores de la KGB.

${ }^{5}$ Como es bien sabido, el original de esta nota, la más famosa de las cuatro que Nietzsche dirigió a Cosima Wagner durante los primeros días de enero de 1889 , no se conserva y se piensa que, igual que otras cartas suyas, fue destruida por la Sra. Wagner como reacción ante la 
A continuación tenemos el texto y el comentario a 14 cartas calificadas de Urabschriften, es decir, aquellas cuyo texto se conserva únicamente gracias a una copia manuscrita realizada por Elisabeth y que despertaron el recelo tanto de Karl Schlechta como de Mazzino Montinari, quienes se abstuvieron de publicarlas en sus respectivas ediciones al considerarlas como burdas falsificaciones. De las 14 cartas aquí transcritas, todo un ejercicio de ingeniería de Elisabeth tomando como base textos de Nietzsche que modificaba, reelaboraba y a los que añadía a veces también el suyo propio, 11 estaban ya señaladas en la famosa lista de Schlechta ${ }^{6}$ y las restantes ni siquiera fueron publicadas en la edición del epistolario realizada por el Archivo Nietzsche ${ }^{7}$ bajo la atenta supervisión de la que, a partir de Richard Roos, se suele calificar como la «soeur abusive» ${ }^{8}$.

La parte central de este volumen es, como no podía ser de otra manera, el aparato crítico que viene precedido, como es habitual, por una breve nota en la que se explica la estructura que se ha seguido para su elaboración y donde se da un listado de las abreviaturas utilizadas. De esta forma, y para cada carta, se nos dice el lugar en el que se conserva el original (o en su defecto el borrador o el fragmento), dónde ha sido publicada con anterioridad, se hace una descripción del manuscrito (esto únicamente para las cartas de Nietzsche), se informa de la fecha y el lugar de destino en el caso de que no se encuentren estos datos de forma manuscrita o bien especificados y se dan las variantes (Lesarten), donde se agrupan las correcciones al texto publicado en la edición Colli-Montinari, las injerencias de los editores así como las versiones previas en el caso de que se hayan conservado algún esbozo de la carta original. Por último, en los comentarios (Erläuterungen) se nos ofrece

publicación de WA. Sin embargo, durante muchos años y hasta la edición Colli-Montinari ha sido dada por válida y, además de aparecer editada por Karl Schlechta (SA n 277, vol. III, p. 1350), la han citado estudiosos como Bernoulli, Andler, Podach o incluso Janz en su ejemplar biografía (p. 24 del volumen cuarto en la edición castellana; p. 28 del volumen tercero del original alemán). El motivo de la definitiva inclusión de la nota en la edición Colli-Montinari ( $\left.{ }^{\circ} 1242 a\right)$ reside en la credibilidad del testimonio que ofrece Peter Gast a Franz Overbeck en una carta fechada el 20 de abril de 1891 en la que éste, a su vez, transmite el testimonio de Elisabeth quien habría sido informada directamente por Cosima Wagner. La carta de Gast se encuentra recogida en Franz Overbeck - Heinrich Köselitz [Peter Gast], Briefwechsel, herausgegeben und kommentiert von David Marc Hoffmann, Niklaus Peter und Theo Salfinger. Berlin/New York, Walter de Gruyter (Supplementa Nietzscheana, Band 3), 1998, pp. 335-337. Para la historia de la fortuna de esta nota, véase el comentario de David Marc Hoffmann, op. cit., pp. 701-702.

${ }^{6}$ Para esta cuestión véase el «Philologischer Nachbericht», en SA III 1410-1417. Las 11 cartas aquí publicadas corresponden a los números 21-29, 31,32 de la lista que ofrece Schlechta en las pp. 1410-1411. La n ${ }^{\circ} 30$, es decir, la carta escrita a Elisabeth el 14 de septiembre de 1888, fue dada por buena en la $2^{\mathrm{a}}$ edición (1960) al aparecer el original. Actualmente se encuentra publicada en KGB III/5 427-429.

${ }^{7}$ Todas estas falsificaciones fueron publicadas en el volumen quinto y último de las Gesammelte Briefe (GBr) Friedrich Nietzsches Briefe an Mutter und Schwester, hg. von Elisabeth Förster Nietzsche, Leipzig: Insel Verlag, 1909.

${ }^{8}$ Roos, Richard, «Elisabeth Foerster-Nietzsche ou la soeur abusive», Études germaniques, 1956, 321-341. 
abundante información que ayuda a situar y clarificar el contexto de cada carta, además de remitirnos a otros escritos de Nietzsche, algo de gran importancia en un periodo en el que, como ya señalaban los editores, se acentúa aún más la conexión del epistolario con las obras y los fragmentos póstumos ${ }^{9}$.

Tras el comentario crítico hallamos la ya habitual, y por desgracia siempre extensa, lista de cartas no conservadas pero de las que se tiene constancia, ya sea porque se han encontrado fragmentos o esbozos, porque se ha conservado el sobre que la contenía o bien porque se hace alusión a ella en otra carta. En total, 87 cartas no conservadas y que fueron escritas por Nietzsche, de las cuales más de la mitad (48) se han publicado ya en KGB III/5 (aunque sólo fragmentariamente o a través de algún esbozo) y 96 dirigidas a él, de las que únicamente 4 están recogidas en KGB III/6 y de forma fragmentaria.

Después encontramos un apéndice que, dicho sea de paso, echamos en falta en algunos volúmenes críticos de las cartas ${ }^{10}$, y que lleva por título «Cartas, recuerdos, reseñas, facsímiles y otros materiales sobre Nietzsche ordenados cronológicamente». Aquí tenemos recogidos 94 documentos de gran valor entre los que cabrían destacar, por ejemplo, las cartas entre terceros (38), las reseñas de sus obras (10 a JBG, 4 a GM y 9 a WA), diversos facsímiles de cartas (en total 13), los relatos de estancias con él (1 de Paul Deussen y 2 de Meta von Salis, quien describe las visitas que realizó a Nietzsche en Sils-Maria en los veranos de 1887 y 1888), el artículo de Karl Spitteler «Friedrich Nietzsche aus seinen Werken» (Friedrich Nietzsche a partir de sus obras), el cual aparece mencionado en $\mathrm{EH}$, «Por qué escribo tan buenos libros», $§ 1$, o bien diversos escritos sobre Nietzsche que aparecieron en la revista Antisemitische Correspondenz editada por Theodor Fritzch y que provocaron su lógica indignación.

Las páginas siguientes contienen un listado de correcciones al texto de las cartas tal y como éstas fueron editadas en los correspondientes volúmenes, unas correcciones que ya habían sido señaladas en el aparato crítico de cada carta, pero que aquí aparecen ordenadas y siguiendo la paginación de KGB III/5 y 6, respectivamente. Como en las demás ocasiones, la lista es extensa (201 para el texto de KGB III/5 y 157 para el de KGB III/6) lo que revela la atenta observación del manuscrito original por parte de los encargados (en este caso únicamente habría que decir, "la encargada") de este volumen. Sin embargo, igual que en las listas aparecidas en los otros comentarios críticos, no deja de haber aquí algunas omisiones, erratas y hasta discrepancias respecto a lo señalado en el aparato crítico.

Por último, el volumen finaliza con un amplio índice onomástico de la sección

\footnotetext{
${ }^{9}$ Unos comentarios no exentos de erratas, imprecisiones y en los que a veces no se aprovechan los descubrimientos de la reciente investigación nietzscheana (véase por ejemplo NietzscheStudien, 26, pp. 575-576, donde Thomas H. Brobjer señala posibles fuentes para la carta a Heinrich Köselitz del 24 de noviembre de 1887 y para la dirigida a Franz Overbeck el 4 de julio de 1887 y que aquí no se recogen). Sin embargo, sí se corrige (pp. 104 y 171) el reiterado error de KGB III/7.2 donde se dejaba fuera SE de la lista de obras editadas por Schmeitzner (véase nuestra reseña a este volumen, cit., p. 221, nota 9).

${ }^{10}$ Como en el I/4, el II/7.2 y el II/7.3.
} 
tercera de la KGB. Como en el índice de las otras dos secciones, la novedad y el avance respecto al publicado en KSB 8, consiste en que éste abarca también las cartas dirigidas a Nietzsche, es decir, en este caso contamos con la inclusión del índice onomástico de los volúmenes III/2, 4 y 6 . No obstante, a diferencia de los índices publicados en KGB I/4 y en KGB II/7 3.2, este índice de la sección tercera no abarca los tres volúmenes del comentario crítico, una deficiencia tan grave como incomprensible y que supone un obstáculo a la investigación del epistolario de este periodo tan crucial de la vida y la obra de Nietzsche.

En definitiva, una excelente aportación a los estudios nietzscheanos que hay que celebrar por la gran ayuda que supone para la comprensión de los dos últimos años de la vida lúcida de Nietzsche. Unos años apasionantes, quizá los que más, y en los que Nietzsche, que se movía entre Niza (inviernos) y Sils-Maria (veranos), que había descubierto Turín (abril 1888) y que empezaba ya a tener admiradores y divulgadores de su filosofía más allá de la necedad de las reacciones críticas provenientes de su ingrata Alemania, desarrolla una actividad frenética, febril incluso, en vistas a la confección de su gran obra (La voluntad de poder o Transvaloración de todos los valores) para la cual el cada vez más solitario y ciego filósofo realizará muchísimas lecturas (Dostoievski, Gebhardt, Baudelaire, Galiani, los hermanos Goncourt, Brochard, Féré, Wellhausen, Tolstoi, Renan, Jacolliot y un largo etcétera que incluye sus propias obras) cuyo eco y diálogo crítico lo hallamos no sólo en las obras que escribe (GM, GD, WA, AC, EH, NW y DD) y en las miles de anotaciones que hizo en sus cuadernos (en KSA, más de la mitad del volumen 12 y todo el 13, es decir, más de mil páginas), sino también, y como es obvio, en su epistolario ${ }^{11}$.

Esperemos, pues, que todo este material sirva de base e instrumento de trabajo a ese nutrido y cualificado grupo de especialistas que está preparando la edición española de las cartas de Nietzsche para la editorial Trotta ${ }^{12}$.

\section{Antonio Morillas Universidad de Barcelona}

\footnotetext{
${ }^{11}$ Para la influencia de estas lecturas en Nietzsche, véase, por ejemplo, además de las numerosas y valiosas colaboraciones, sobre todo de Giuliano Campioni y Thomas H. Brobjer, en la sección «Beiträge zur Quellenforschung» del Nietzsche-Studien, el artículo de éste último «Nietzsche's Reading and Private Library, 1885-1889 » publicado en Journal of the History of Ideas, 58/4 (1997), 663-693.

${ }^{12}$ La descripción de este proyecto, dirigido y supervisado por Luis de Santiago Guervós, se encuentra en Estudios Nietzsche, 4 (2004), 241-242.
} 
